\title{
Non-synthetic sources for the development of hydroxyapatite
}

\begin{abstract}
The number of patients suffering from different kind of tissue related diseases is increasing rapidly and researchers are earnestly looking for alternative source for producing biomaterials that can meet the demand. Commercially sourced hydroxyapatites are from synthetic origin and of high cost. Hence, the utilization of agricultural wastes as source of hydroxyapatite is of great interest. Therefore, this work considered the importance of biomaterials and the various types of emergent agro-wastes that have been utilized for hydroxyapatite production in recent time and, hence, encourage more research in this area of interest.
\end{abstract}

Keywords: hydroxyapatites, agricultural wastes, biomaterials, synthetic, development
Volume 5 Issue 2 - 2018

\author{
Oladele IO,' Agbabiaka OG,' Olasunkanmi \\ OG, ${ }^{2}$ Balogun AO,' Popoola MO' \\ 'Department of Metallurgical and Materials Engineering, Federal \\ University of Technology, Nigeria \\ 2Department of Chemistry, Federal University of Technology, \\ Nigeria
}

Correspondence: Oladele IO, Department of Metallurgical and Materials Engineering, Federal University of Technology Akure, PMB 704, Ondo State, Nigeria, Tel +234-08034677039, Email iooladele@futa.edu.ng,wolesuccess2000@yahoo.com
Abbreviations: PU, polyurethane; PET, polyethylene terepthalate; PEEK, polyetheretherketone; SR, silicone rubber; $\mathrm{CF}$, carbon fiber; CUABB, clemson university advisory board; PGA, polyglycolic acid; PLA, polylactic acid; PLGA, polylactid-coglycolic acid; FDA, food and drug administration

\section{Introduction}

Biomaterials are materials that are widely used for replacing and/ or restoring worn out or traumatized tissues or organs to improve the quality of life of patients. These materials are either used in form of implants (vascular grafts, heart valves, stents, ligaments, dental implants, etc.) or in form of medical devices such as biosensors, peacemaker, artificial hearts, etc..$^{1-3}$

The evolution of biomaterials can be traced back to several thousand years of the Aztecs, Chinese and Roman. They used gold in dentistry, while wood, glass, Ivory, and some other materials were used as implants for treating long bone fractures. The use of metallic devices for bone construction began in late 1700s, however, by then, it was difficult to discern between good and bad materials for use as implants because majority of these materials are infection carriers. It was not until 1860 s that Lister worked on biomaterials in such a way that they could be used without transmitting infection to their host. ${ }^{4}$ Ever since then, considerable progress has been made using biomaterials for orthopaedic implants, dental implants, vascular stents and artificial hips as shown in Figure 1.

The increasing importance of biomaterials in our society today can be traced in a number of ways, including the growth of biomaterials in the industry and as an academic discipline. There is a tremendous rise in scientific publications in the biomaterials field for over three decades, as well as the creation of several academic departments of biomedical engineering that spread across many nations. ${ }^{1,5}$ The subjects of biomaterials are interdisciplinary as shown in Figure 2, which include chemistry, biology, physics, mechanics, materials science, chemical engineering, bioengineering, and medicine, with a considerable input from ethicists, entrepreneurs and government organizations. ${ }^{6}$

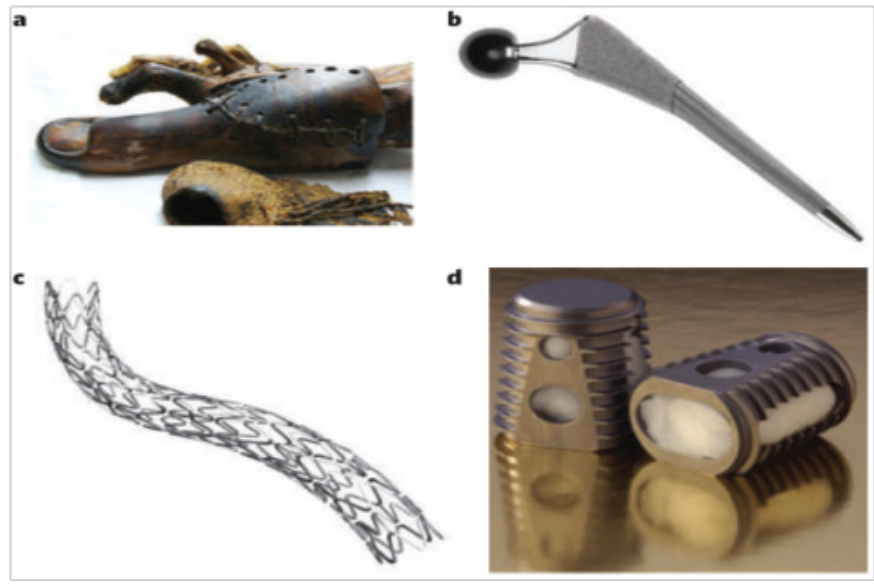

Figure I History and growth of biomaterials as a field and industry.

A. Prosthetics fashioned from wooden toes.

B. The synergy hip implant.

C. A metallic stent from paclitaxel.

D. A bone graft device.'

Currently, a wide variety of materials encompassing all the conventional materials such as polymers (polyurethane (PU), polyethylene terepthalate (PET), polyetheretherketone (PEEK), silicone rubber (SR), HDPE, etc.), ceramics (carbon, zirconia, bioglass, alumina, hydroxyapatite, etc.), metals (gold, titanium alloy, tantalum, stainless steel, etc.), and composites (HAp/epoxy, HAp/ HDPE, carbon fiber (CF)/epoxy, CF/PEEK, etc.), have been studied as biomaterials. These materials are designed to mimic or interact with body cells and tissues in a special and predictable ways, and must be noncarcinogenic, nontoxic, chemically inert, and mechanically strong to be able to withstand repeated loading conditions of a lifetime. ${ }^{2}$ Nowadays, agricultural wastes (agro-wastes) are being utilized as biomaterials for use in therapeutics and medical surgery. This is 
because some of the wastes contain some valuable compounds that are required in biomedical applications. This is a novel practice that is anticipated to add value to biomedical field and agro-wastes for human consumption. Most of the reported waste materials are proven to serve as biomaterial substitutes for tissue repair and have attracted significant interest because of the rise in the number of patients suffering from tissue related problems.?

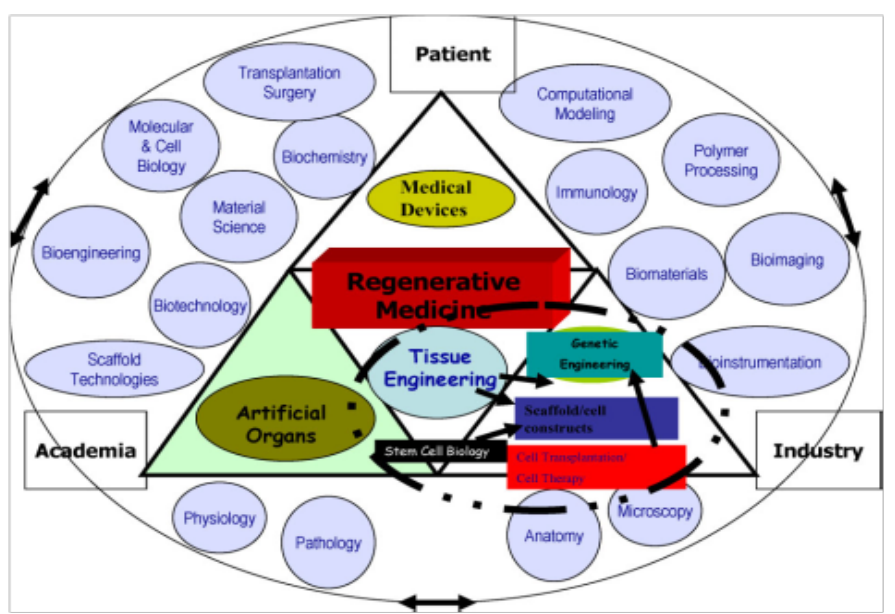

Figure 2 Summary of multidisciplinary field of tissue engineering and regenerative medicine. ${ }^{6}$

There is no doubt that the field of biomaterials has experienced a consistent growth and a steady introduction of unprecedented ideas and prolific branches. A new generation of agro-waste biomaterials that focuses on the biology of inflammation and wound healing is emerging. Such biomaterials are being investigated for both cell carriers and drug delivery. However, this review paper will judiciously elaborate on selected agro-waste biomaterials, selection criteria and functionalities.

\section{Classification of biomaterials}

The wide range and sophistication of biomaterials currently used in biomedical applications is a testimony to the noteworthy technological advances which are experienced for the past decades. The performance of biomaterials can be classified according to the roles they played in the body. For instance, some biomaterials are applied as implants to replace and interact with certain part of a living system. This point was suggested by the Clemson University Advisory Board (CUABB) for biomaterials and mentioned that biomaterials that are used as implants are called implantable biomaterials. ${ }^{8}$ Another class of biomaterials are used as medical devices to support and enhance the functionality of the living system. In general, biomaterials are classified as follows:

\section{Metallic biomaterials}

Metallic biomaterials are the first materials to be used in biomedical field. In the early days, the metals and alloys that are developed specifically for human use are "vanadium steels" which was used for building bone fracture screws and plates (Sherman plates) and "gold" which was used in dentistry. Most metals such as cobalt (Co), chromium $(\mathrm{Cr})$, iron $(\mathrm{Fe})$, titanium $(\mathrm{Ti})$, nickel $(\mathrm{Ni})$, tantalum $(\mathrm{Ta})$, tungsten (W), molybdenum (Mo) and niobium $(\mathrm{Nb})$, that are used for making metallic implants can only be permitted in the body for little time. ${ }^{2}$ Sometimes, naturally occurring metallic elements are needed for vitamin B-12 synthesis and red blood cell recuperation, but cannot be tolerated in the body in large amount. However, there is serious concern about the biocompatibility of metallic implants due to their high tendency to corrode in the body. ${ }^{9}$ Hence, the aftermaths of corrosion are the decomposition of the metallic implants via weakening effect, and the release of harmful substances into the surrounding tissues and organ during corrosion. ${ }^{10}$

\section{Ceramic biomaterials}

Generally, ceramics are hard and encompass a wide range of non-metallic and inorganic compositions which are mostly used for bone repair and/or replacement. The ceramics used in producing implants can be classified as biodegradable (non-inert), bioresorbable, bioactive (semi-inert) and nonabsorbable. Zirconia, carbon, silicon nitride and alumina are inert bioceramics. Some dense hydroxyapatite and glass ceramics are semi-inert (bioreactive); calcium aluminates and calcium phosphates are bioresorbable ceramics. ${ }^{11}$ The use of ceramic biomaterials as scaffold materials have be discouraged due to their brittleness and low fracture toughness. ${ }^{12}$ To overcome these drawbacks, ceramics are combined with polymers in form of particles to develop composites for biomedical application. Thus, ceramic biomaterials have enhanced the mechanical properties and bioactive functions of the composites in in vivo. ${ }^{2}$

\section{Polymeric biomaterials}

Polymeric biomaterials have been extensively used in medical disposable supplies, dental materials, vascular grafts, wound dressing, implants, prosthetic materials, extracorporeal devices, orthodoses, encapsulants, drug delivery systems, and tissue engineered products, like those of ceramics and metallic biomaterials. The main advantages of using polymeric biomaterials are ease of processing and manufacturing to form various shapes (films, latex, fibers, sheet, etc.), low cost, light weight, and flexibility. However, polymers generally lack bioactive functions and are too weak to meet the mechanical requirements in orthopaedic surgery. ${ }^{13}$

Synthetic biodegradable polymeric biomaterials are mostly considered for developing scaffolds in tissue engineering. Particularly, polyesters such as polyglycolic acid (PGA), polylactic acid (PLA) and polylactic-co-glycolic acid (PLGA). Polydioxane, PLA and PGA, have been used extensively by the USA Food and Drug Administration (FDA). ${ }^{8}$ The biodegradation of these polymers involves the enzymatically and hydrolytically disintegration of polymer bonds, thereby resulting to polymer erosion. Depending on the mode of degradation, biodegradable polymeric biomaterials can be classified into enzymatically degradable polymers and hydrolytically degradable polymers. Although, enzymatically degradation is the most common. ${ }^{14}$

Irrespective of polymer degradation mode, biodegradable polymeric biomaterials can be classified into biodegradable and bioresorbable polymeric biomaterials. Polymer erosion can exist on polymer surfaces or in the entire polymer volume, as a result of material loss caused by water penetration into the polymer interfaces. Generally, polymers are hydrophobic, and can prevent water from penetrating into them. To allow water penetration, some specific hydrophilic bioactive agents are added to them which absorb water into the polymer structure via hydroxyl ion exchange. Hence, the 
"eroded polymeric materials" can be reabsorbed (bioabsorbable polymers) in the body only if the bioactive agents are removed from the body via excretion. ${ }^{15,16}$

On the basis of long service life clinical requirement, synthetic non-degradable polymeric biomaterials are the most suitable for tissue engineering applications. Common examples of such polymeric biomaterials are high density polyethylene, polytetrafluoroethylene, poly (vinyl chloride), polypropylene, poly (methyl methacrylate), polycarbonate, poly (ether ether ketone), polysulphone, polyoxymethylene and polyamides. They are also biostable and are widely considered for various orthopaedic applications. ${ }^{17}$

\section{Composite biomaterials}

Composite biomaterials can also be referred to as 'biocomposites'. Biocomposites are biomaterials having at least two or more biomaterials coming together as distinct separate bioactive phases (matrix and reinforcement), whose properties are significantly altered compared to that of homogeneous biomaterials. ${ }^{18} \mathrm{~A}$ schematic diagram showing the classification of man-made polymer biocomposites is shown in Figure 3.

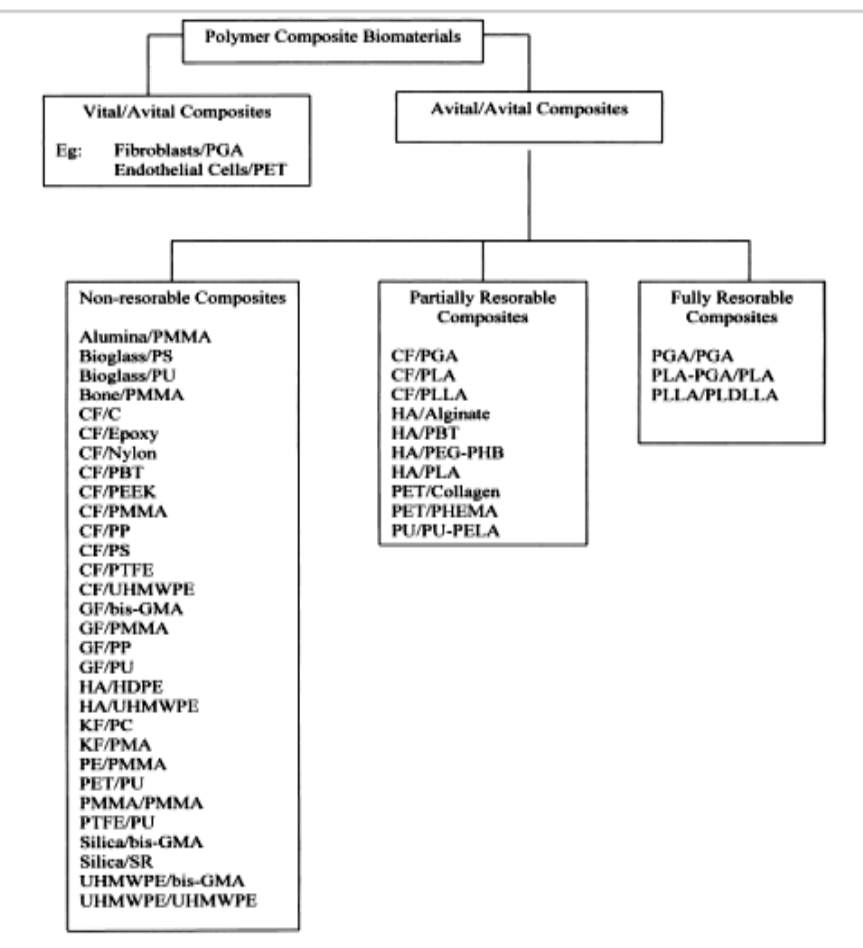

Figure 3 Classification of man-made polymer biocomposites. ${ }^{19}$

Biocomposite usually consists of a matrix and reinforcements which could be in form of fibres or particles but must be biocompatible. For instance, fiber reinforced plastics such as fiber glass and some other natural materials like teeth and bone are regarded as biocomposites, but alloys such as bronze and steel are not. However, potential problems of using biocomposites in medicine are due to their high tendency to degrade and be reabsorbed by the body environment. Therefore, a biocomposite must be designed to withstand any environmental conditions (thermal, chemical or mechanical actions) it is subjected to, without causing any degradation to its interface. ${ }^{20}$ An exception to this practice is when the biocomposite degradation product(s) are needed for drug delivery at a given period of time. ${ }^{21,22}$ Some of the areas of application of polymer composite biomaterials is shown in Figure 4.

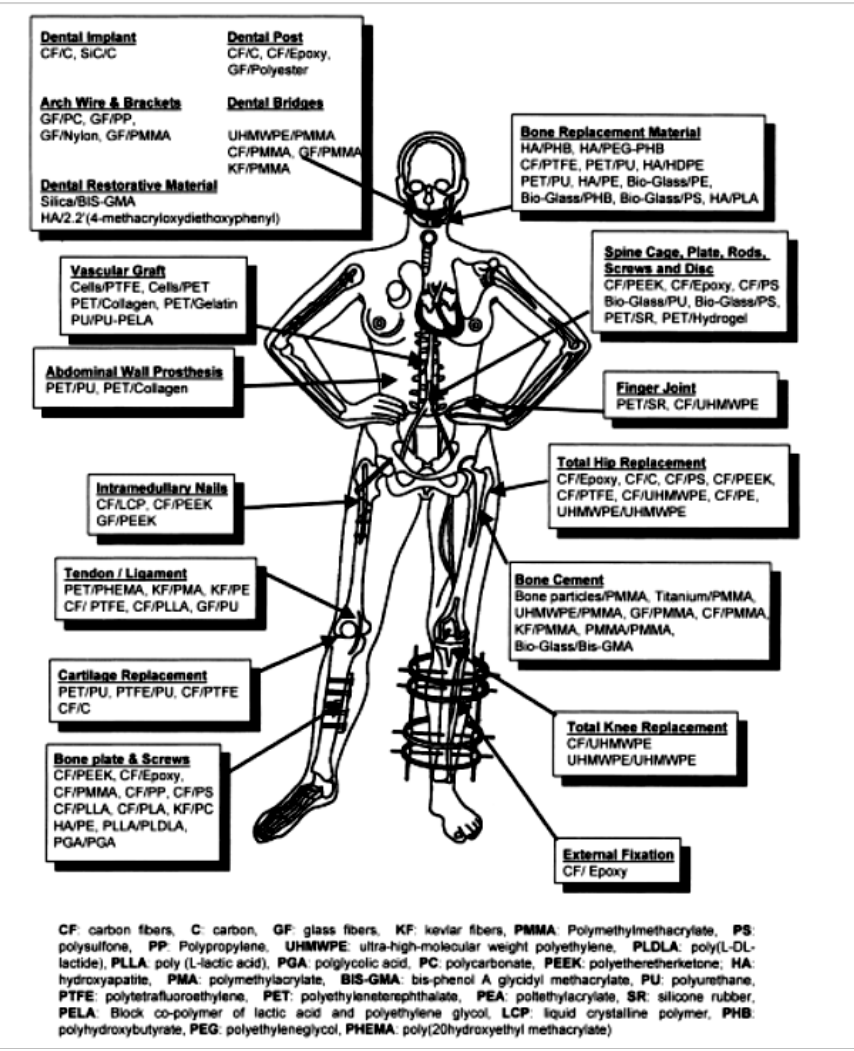

Figure 4 Various applications of different polymer composite biomaterials. ${ }^{22}$

\section{Selection criteria for biomaterials}

A material that is selected for use as biomaterial must possess certain important characteristics to avoid possible body inflammation and rejection. ${ }^{19}$ Some of the characteristics must be factored in at the early stage of the designing and manufacturing processes. However, some specific properties required in the biomedical field are discussed in the following sections.

\section{Biocompatibility}

In recent years, researchers have tried to include the word "biocompatibility" to the definition of biomaterials. For a material to be biocompatible it must be able to function appropriately within the body system without showing any sign of inflammation or pyrogenicity or causing any kind of reactions. ${ }^{23}$ In essence, not all biomaterials are biocompatible but all biocompatible materials are biomaterials. For the purpose of simplicity, the term "biocompatibility" should reflect the harmony between the biomaterial and body system. Therefore, it is always safer to ensure that biomaterials are biocompatible by conducting thorough in vitro investigation before using it in the body system.

\section{Host response}

Host response signifies the response of a host organism to the 
implanted biomaterial..$^{24}$ It is expected that the patient must respond well after the implantation procedure. For instance, when a biomaterial is implanted in the body, it induces certain response known as foreign body response as illustrated in Figure 5. These responses are caused by protein adsorption, cell integration, cell reformation, cytokine release and vascular rebuilding. Most of these responses have been studied extensively in the literature. The point is that every response contributes to the healing process of the patient and if the biomaterial is not suitably implanted, there is high tendency for the patient to develop sign of discomfort at each stage of the healing process. ${ }^{25}$

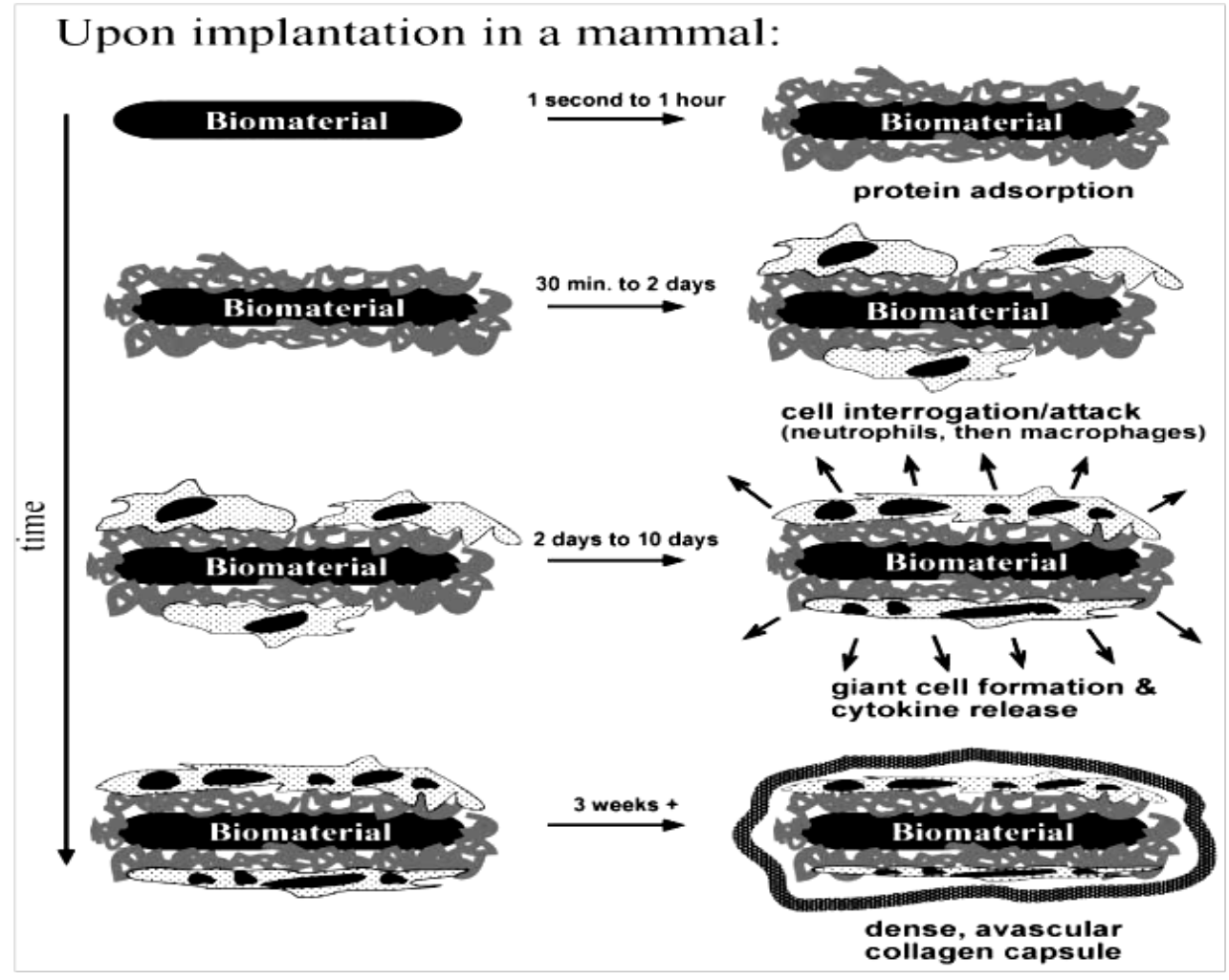

Figure 5 The foreign body reaction as illustrated is the normal reaction showed by mammals to an implanted synthetic material. ${ }^{8}$

\section{Biofunctionality}

A biomaterial must be designed to withstand any physical or mechanical actions it is subjected to. Here, the biofunctionality of a biomaterial is essential to be included as part of the requirements necessary for its fabrication. Some of the design requirements of biomaterials are:

i. Load transmission, stress distribution and fracture toughness (required for bone replacement)

ii. Blood control and fluid flow (required for artificial heart)

iii. Articulation to allow body movement (required for artificial knee joint replacement)

iv. Electrical responses (required for peacemaker)

v. Sound transmission (required for cochlear implant)

vi. Light transmission (required for implanted lenses)

vii. Space filling (required for carrying out cosmetic surgery) ${ }^{2}$

\section{Toxicology}

Toxicology in biomaterials deals with the study of poisonous effect of biomaterials with their host response. It also deals with the toxicity of the substances that migrate out of biomaterials after their possible degradation. Although, it is expected that a biomaterial should not be toxic, unless it is specifically design for such requirement. For instance, some biomaterials are engineered as drug delivery agents to destroy cancer cells in the body. These biomaterials are implanted in the body as "smart bombs" in which after some time they will be allowed to detonate and diffuse into the body streams to kill any cancerous agents. ${ }^{2}$

\section{Mechanical properties of biomaterials}

The mechanical properties of biomaterials are very crucial when designing biomaterials for load bearing applications. Mechanical properties such as tensile strength, Young's modulus, tensile strength at yield, fatigue, creep and hardness, are the most essential properties that must be carefully studied and analysed for such application. ${ }^{26}$

\section{High corrosion resistance}

Biomaterials must exhibit high corrosion resistance because of their exposure to corrosive body fluid. Corrosion of biomaterial is unavoidable especially for metallic biomaterials because metallic implants release unwanted metallic ions that are detrimental to both 
the implant (in terms of its lifespan) and the patient's wellbeing. Most times, the patient will have to undergoes repeated surgery due to implant loss as a result of corrosion. This is why doctors are using high corrosion resistance biomaterials such as polymer-based biocomposites to replace metallic ones. ${ }^{27}$

\section{High wear resistance}

It is expected that implantable biomaterials should exhibit high wear resistance in order to avoid loosening effect at the spot of implantation. During wearing, some wear debris are generated which are not biologically active in most cases. As a result, causes a severe inflammatory response that leads to service life reduction of the implant, as well as destroying the body host that supports the implant. ${ }^{28}$

\section{Application of biomaterials}

The uses of biomaterials can be grouped into two:

\section{i. Medical uses}

ii. Non-medical uses

\section{Medical use}

The term "medical use" refers to the use of biomaterials as implants in the body systems. As shown in Figure 4, examples of such implants are: cochlear implant, dental implant, joints (knee, hip and shoulder), intraocular lens, peacemaker, stent, feeding tube, artery graft, glaucoma drainage tube, mechanical heart valve, tissue adhesive, nerve guide tube, etc.

\section{Non-medical use}

The term "non-medical use" means the application of biomaterials for any purpose outside the body system. It could be the use of biomaterials for in vitro testing or for making medical actuators and sensors. Typical examples of non-medical use of biomaterials are: yeast array chip, bioremediation materials, cell culture, nanoelectromechanical systems (NEMS), microelectromechanical systems (MEMS), fuel cells, artificial muscles, actuators, biosensor, electrophoresis materials, smart clothing for biowarfare, chromatography, biomimetics, biofouling-resistant materials, arrays of DNA and diagnostics.

\section{Biomaterials from agro-wastes}

Agro-wastes are any waste generated in accumulation or concentration from farm processes. The wastes are ignorantly disposed into the surrounding because many people are unaware that some of these wastes contain certain valuable substances that can be used for material development. Moreover, disposal of any kind of wastes into the environment especially when their accumulation is in excess can become a serious problem for animals, humans, and vegetations. To enable sustainable environment, researchers have started studying the conversion of agro-wastes into meaningful products for the benefit of mankind. ${ }^{29}$

One of the many ways of adding value to agro-wastes is to utilize it as biomaterials for biomedical applications. Interestingly, some of the wastes contain some bioactive compounds that are beneficial in biomedical applications. This is a unique practice that is expected to add another dimension to agro-wastes utilization. Many of the researches on agro-wastes mainly focused on energy generation, renewable raw materials, and chemical feedstock. ${ }^{7}$ The development of biomaterials from agro-wastes is an emerging field that is attracting a lot of interest because of the rise in the number of patients that required implantable biomaterials to solve their tissue related problems..$^{5,30-32}$

This review paper gives an insight into the utilization of agro-wastes to produce hydroxyapatite for biomedical applications. For instance, eggshell is one of the many examples of agro-wastes that remains the largest untapped and untransformed agro-waste material, and are ignorantly discarded into the surrounding due to its low economic value. Eggshell contains high percentage of calcium carbonate that is useful for producing hydroxyapatite, a major inorganic portion of bone and teeth. ${ }^{33}$ The following section shall discuss on the relevance of selected agro-waste sources for hydroxyapatite in tissue engineering.

\section{Hydroxyapatite}

Hydroxyapatite is a synthetic biomaterial with chemical composition $\left(\mathrm{Ca}_{10}\left(\mathrm{PO}_{4}\right)_{6}(\mathrm{OH})_{2}\right)$ similar to that of bone and hard tissue and, therefore, it can be used for coating on bone implants or as a filler to replace damaged bone or teeth. The atomic structure of hydroxyapatite is presented in Figure 6. It is exceptionally bioactive and biocompatible with respect to tissue and bone cells, probably because of its resemblance with the body tissues. To date, hydroxyapatite has been widely used in medicine in the form of granules, powders, dense porous blocks and composites. . $^{6,34,35}$

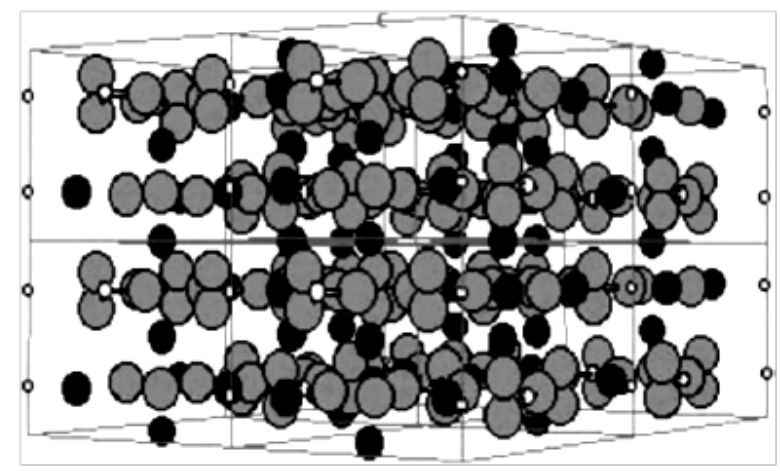

Figure 6 Atomic structure of hydroxyapatite; phosphorus, oxygen and calcium are the smallest white atoms, largest gray atoms and medium black atoms, respectively. ${ }^{16}$

Mammalian bone and teeth consist of Ca (24 wt\%), P (10 wt\%), protein $(22 \mathrm{wt} \%)$, and some other elements in trace amount such as $\mathrm{Zn}^{2+}, \mathrm{Mg}^{2+}, \mathrm{Mg}^{2+}, \mathrm{K}^{+}, \mathrm{Ba}^{2+}, \mathrm{F}^{-},\left(\mathrm{CO}_{3}^{2-}\right)$ etc. These trace elements play a very important role in the life cycle of mammalian hard tissue; therefore, scientists are looking for various means to incorporate these elements into the structure of artificially made hydroxyapatite to impart better osteoconductive properties. ${ }^{36}$ In natural bones, hydroxyapatite exists as an irregular nanometre thin plates of carbonate $\left(\mathrm{CO}_{3}^{2-}\right)$ apatite with an average length and width of $50 \mathrm{x}$ $25 \mathrm{~nm}$ and thickness of 2-3 nm. However, it still remains a challenge to develop hydroxyapatite with mineral components that completely match that of mammalian hard tissue. ${ }^{37}$

In order to attain maximum resemblance of mineral constituents with that of natural bones, some selected natural resources such as 
eggshells, plants, seashells, fish bones, etc., are under extensive study to develop a bone-like hydroxyapatite for biomedical applications. Other related compounds of hydroxyapatite are calcium phosphate (CP-based) biomaterials with $\mathrm{Ca} / \mathrm{P}$ molar ratio ranging from 0.5 to 2 , and are also useful in tissue reconstruction especially in dentistry and orthopaedic surgery. ${ }^{37}$

\section{Selected sources for hydroxyapatite synthesis}

Animal bones: Thus far, hydroxyapatite has been synthesized using different materials and methods that require strict control of process parameters to produce high quality stoichiometric hydroxyapatite. A typical synthetic hydroxyapatite has a stoichiometric $\mathrm{Ca} / \mathrm{P}$ ratio of 1.67 , of which the hydroxyapatite derived from animal bones is non-stoichiometric due to the presence of some trace elemental ions and as a result it is regarded as a potential candidate for bone graft purposes. ${ }^{38}$

Generally, hydroxyapatite exists in form of needles, spheres, rod, etc., and is usually produced from either synthetic chemicals or natural bone ash. The efficiency, properties, purity and size distribution of hydroxyapatite synthesized from natural bones are dependent on factors like bone condition, calcination temperature and method of synthesis. Bovine bones are usually selected for preparation of hydroxyapatite based scaffolds for bone regeneration purposes. In general, any bone selected for investigation are thoroughly with boiled and distilled water, followed by dissolution in $\mathrm{NaOH}$ solution to remove proteins and some other impurities from the surface of the bones. Afterward, the dried bones are cut into small pieces of different sizes using a ball mill for as many times as possible, which may in turn affects the physical characteristics of the final product. During the calcination stage, bone particles are heated in a furnace controlled at different temperatures between 600 and $1400^{\circ} \mathrm{C}$ to completely eliminate the organic matter present in the bone and deliver the hydroxyapatite. Proper selection of calcination treatment is required to enhance the crystallinity of hydroxyapatite without causing thermal degradation of the final hydroxyapatite. Furthermore, any pathogens or diseases that may be transferred from selected mammal to patient are destroyed during the calcination treatment. ${ }^{37}$

X-ray diffraction (XRD) analysis of calcined bone particles confirms the presence of pure hydroxyapatite phase and some characteristic peaks at (220), (200) and (311) Ag planes, which are existing as separate phases. Studies have shown that the hydroxyapatite derived from defatted animal bone possessed low degree of crystallinity and can only be improved upon by alkaline treatment. Calcined bone exhibits the highest degree of crystallinity and is suitable for biomedical applications compared to alkaline treated defatted bone. Scanning electron microscopy (SEM) analyses of calcine bone corroborate the formation of spherical crystallites. Hence, animal bones especially bovine bones represent a viable source for hydroxyapatite synthesis. ${ }^{37}$

Aquatic sources: Aquatic sources encompass fisheries which contributes to over $50 \%$ of global total fish consumption. The consumption of fish and crustacean results to the accumulation of large quantities of calcium and hydroxyapatite rich waste. Hence, aquatic wastes have been investigated for producing various kind of biomaterials. ${ }^{39}$ Recently, research has showed that CP-based hydroxyapatites are present in laboratory fish bones. Fish bones are rich in calcium, carbonate and phosphate and can be used for synthesizing hydroxyapatite. ${ }^{40}$ Normally, fish bones are used for dietary purpose due to its high calcium content, however, a few attempts have been made to utilized it to produce hydroxyapatite for biomedical applications. To transform fish bones or related sources into hydroxyapatite, these bones are thoroughly washed, boiled and alkalinise to remove all the proteins and some other impurities. Thereafter, it is subjected to calcination treatment at a high temperature to furnish hydroxyapatite. ${ }^{37}$

In contrast to hydroxyapatite prepared from bovine bones, hydroxyapatite prepared from aquatic source (e.g. fish bones) is thermally stable at higher temperatures up to $1200^{\circ} \mathrm{C}$. XRD analysis of both alkaline treated and untreated fish bones revealed a poorly crystalline hydroxyapatite for untreated fish bones. The alkaline treatment is essential for obtaining excellent crystallinity and particle size distribution. SEM study on fish bones usually reveals a spherical shape hydroxyapatite which makes fish bone a suitable source for biomedical applications. ${ }^{37}$

Plant sources: So far, efforts to generate biomimetic derived hydroxyapatite are insufficient, however, researcher are looking for means to introduce new natural resources to synthesize hydroxyapatite. As a result, certain calcite rich plants such as wood and algae are being studied for biomedical scaffolds. ${ }^{41}$ Wood is utilized for scaffold templates due to its organized microstructural cellular hollow tubes which contributes to its high strength, toughness and stiffness. The conversion of wood to hydroxyapatite involves the following steps: (a) production of carbon template, (b) conversion of carbon template to calcium carbide, (c) formation of calcium oxide, (d) formation of calcium carbonate using calcium oxide as precursor, and (e) production of hydroxyapatite via hydrothermal phosphatization. ${ }^{37,42}$

Marine species like corals and red algae (Phymatolithon Calcareum) contains calcite $\left(\mathrm{CaCO}_{3}\right)$ that resembles that of human bones with respect to their interconnectivity and porosity, hence, can be used for synthesizing hydroxyapatite. Red algae calcite is converted to hydroxyapatite via pyrolysis and hydrothermal method. The technique involves calcination treatment of calcite in the presence of magnesium nitrate and diammonium hydrogen phosphate (DAHP). SEM study revealed the presence of porous algae capable of supporting cell adhesion as confirmed by biocompatibility testing. ${ }^{43}$

Hydroxyapatite can be synthesized from the stalks and leaves of green tea, khat, mint, trifolium and basil. The XRD results found in the literature have shown that basil leave contains hydroxyapatite as the main phase together with calcium hydroxide in trace amount. Although, some authors reported the possible presence of other ions but without any substantive data to support their claim. ${ }^{37}$

Biogenic sources: Over a million tons of eggshells are disposed yearly around the world. They are produced as wastes in large amount from houses, bakeries, restaurants, and hatcheries. Likewise, some seashells and other calcium-rich materials are present in huge amount around the world. Eggshells are readily available and cheap and can serve as good source for producing hydroxyapatite in large quantities. $^{37,44}$

Seashells and eggshells are classified under biogenic sources of hydroxyapatite and are considered as better choice to synthesize biomaterials that are biocompatible with the human body. Meanwhile, eggshell as biomaterial source has been briefly discussed in the previous section. Seashell like mollusc shell (Pomacea Lineata) contains about $97 \% \mathrm{CaCO}_{3}$ and can withstand high mechanical strength compared with other shells. 
To synthesize hydroxyapatite, mollusc shells are washed thoroughly with boiled water to remove dirt and some adherent impurities before they are pulverized into powder using a ball mill and then calcined at elevated temperature to give $\mathrm{CaO}$. The obtained $\mathrm{CaO}$ is then mixed with phosphoric acid to prepare hydroxyapatite according to equations 1 and 2. Fourier transform infrared (FTIR) analysis confirms the formation of hydroxyapatite. It is noted that the obtained hydroxyapatite is a carbonated type $\left(\mathrm{CO}_{3}^{2-}\right)$ that constitutes the inorganic part of bone, teeth and enamel, although in a varied amount. The $\mathrm{CO}_{3}^{2-}$ exchanges within the apatite structure to impart better the biomineral activities of the tissues. SEM analysis revealed a flower-like interconnected spongy arrangement. Therefore, the derived hydroxyapatite is a suitable candidate for dental and bone applications. $^{45}$

$$
\begin{gathered}
\mathrm{CaCO}_{3} \rightarrow \mathrm{CO}_{2}+\mathrm{CaO} \ldots \ldots \ldots \ldots \text { (1) } \\
10 \mathrm{CaO}+10 \mathrm{H}_{2} \mathrm{O}+6 \mathrm{H}_{3} \mathrm{PO}_{4} \rightarrow \mathrm{Ca}_{10}\left(\mathrm{PO}_{4}\right)_{6}(\mathrm{OH})_{2}+18 \mathrm{H}_{2} \mathrm{O} \ldots
\end{gathered}
$$

\section{Comparative cost study}

The cost of producing hydroxyapatite from synthetic sources is usually higher than that obtained from non-synthetic sources. The major cause was that the market of synthetic-based hydroxyapatite is driven by price growth, cost of reagents and gross revenue. These key factors are directly dependent on the region, company and type of technique. ${ }^{46}$ In contrast, the cost of extracting hydroxyapatite from natural origin (non-synthetic) is only constrain to the availability of donating patient which could be dead or alive and also sundry cost. ${ }^{47}$ Imagine the challenge that may be posed if no patient is willing to donate their tissue for hydroxyapatite extraction. Nevertheless, producing hydroxyapatite from agro-wastes could be a potential means of overcoming the above mentioned hurdles, considering the fact that the valuable wastes are readily available at no cost especially in Nigeria and are of low cost in many other nations across the globe. Oladele et al., ${ }^{48}$ used Giant African snail shell (Achatina fulica) obtained from farm plantation at no cost to synthesized hydroxyapatite powder and from the results; the research shows that the developed composites were compatible structurally as an implant. However, further works was recommended on biocompatibility of the composites $^{49}$ as well as its porosity level. Hence, encouraging more research in this area can result to producing hydroxyapatite ${ }^{40,45}$ in large quantities at a competitive cost.

\section{Conclusion}

Due to the growing need of biomaterials to solve biomedical related problems, researchers have started utilizing available agricultural wastes to develop biomaterials in large amount. This review paper identifies the emergent agro-wastes that are employed for the production of hydroxyapatite which serves as an alternative inorganic source in bones and tooth due to their similar biomineral constituents. Therefore, more works are expected to continue in this area of research interest.

\section{Acknowledgement}

None.

\section{Conflict of interest}

The authors declare that there is none of the conflicts.

\section{References}

1. Huebsch N, Mooney DJ. Inspiration and application in the evolution of biomaterials. Nature. 2009;462(7272):426-432.

2. Patel NR, Gohil PP. A review on biomaterials: scope, applications \& human anatomy significance. International Journal of Emerging Technology and Advanced Engineering. 2012;2(4):91-101.

3. Oladele IO, Isola BA. Development of Bone Particulate Reinforced Epoxy Composite for Biomedical Application. Journal of Applied Biotechnology Bioengineering. 2016;1(1):00006.

4. Bergman RM. Innovations in biomaterials: achievements and opportunities. MRS bulletin; 2005;30(7):540-545.

5. Lindfors N, Geurts J, Drago L, et al. Antibacterial Bioactive Glass, S53P4, for Chronic Bone Infections-A Multinational Study. Adv Exp Med Biol. 2017;(5):81-92.

6. Hutmacher DW, Schantz JT, Lam C, et al. State of the art and future directions of scaffold $\square$ based bone engineering from a biomaterials perspective. J Tissue Eng Regen Med. 2007;1(4):245-260.

7. Abdulrahman I, Tijani HI, Mohammed BA, et al. From garbage to biomaterials: an overview on egg shell based hydroxyapatite. Journal of Material. 2014.

8. Ratner BD, Bryant SJ. Biomaterials: where we have been and where we are going. Annu Rev Biomed Eng. 2004;(6):41-75.

9. Balamurugan A, Rajeswari S, Balossier G, et al. Corrosion aspects of metallic implants-an overview. Materials and corrosion. 2008;59(11):855-869.

10. Srivastav A. An overview of metallic biomaterials for bone support and replacement. In Biomedical Engineering, Trends in Materials Science. 2011.

11. Park JB. Bronzino JD. Biomaterials: principles and applications. crc press; 2002.

12. Yarlagadda PK, Chandrasekharan M, Shyan JY. Recent advances and current developments in tissue scaffolding. Biomed Mater Eng. 2005;15(3):159-177.

13. Parida P, Behera A, Mishra SC. Classification of Biomaterials used in Medicine. International Journal of Advances in Applied Sciences. 2012;1(3):125-129.

14. Boccaccini AR, Blaker JJ. Bioactive composite materials for tissue engineering scaffolds. Expert Rev Med Devices. 2005;2(3):303-317.

15. Hutmacher D, Hürzeler MB, Schliephake H. A review of material properties of biodegradable and bioresorbable polymers and devices for GTR and GBR applications. Int $J$ Oral Maxillofac Implants. 1996;11(5):667-678

16. Pielichowska K, Blazewicz S. Bioactive polymer/hydroxyapatite (nano) composites for bone tissue regeneration. Biopolymers. 2010;(12):97-207.

17. Dhandayuthapani B, Yoshida Y, Maekawa T, et al. Polymeric scaffolds in tissue engineering application: a review. International Journal of Polymer Science. 2011.

18. Dorozhkin SV. Calcium orthophosphate-based biocomposites and hybrid biomaterials. Journal of Materials Science. 2009;44(9):2343-2387.

19. Ramakrishna S, Huang ZM, Kumar GV, et al. An introduction to biocomposites, World Scientific. 2004;(1).

20. Lau KT, Ho MP, Au-Yeung CT, et al. Biocomposites: their multifunctionality. International Journal of Smart and Nano Materials. 2010;1(1):13-27. 
21. Wang M. Developing bioactive composite materials for tissue replacement, Biomaterials. 2003;24(13):2133-2151.

22. Venugopal J, Prabhakaran MP, Low S, et al. Nanotechnology for nanomedicine and delivery of drugs. Curr Pharm Des. 2008;14(22):2184-2200.

23. Williams DF. Definitions in biomaterials. Proceedings of a consensus conference of the European Society for Biomaterials; England: Chester; 1987. 4 p.

24. Boretos JW, Eden M. Contemporary biomaterials: Material and host response, clinical applications, new technology and legal aspects. Journal of Membrane Science. 1984;21(2):209.

25. Ratner BD, Hoffman AS, Schoen FJ, et al. Biomaterials science: an introduction to materials in medicine. Academic press; 2004.

26. Oladele IO, Adewole TA. Influence of cow bone particle size distribution on the mechanical properties of cow bone-reinforced polyester composites. Biotechnology research international. 2013. 5 p.

27. Okazaki Y, Gotoh E. Comparison of metal release from various metallic biomaterials in vitro. Biomaterials. 26(1):11-21.

28. Park JB, Lakes RS. Biomaterials: an introduction. Springer Science and Business Media. 2007.

29. Oliveira DA, Benelli $\mathrm{P}$, et al. A literature review on adding value to solid residues: egg shells. Journal of cleaner production. 2013;(46):42-47.

30. Xiang Z, Lu F. Chemicals, Energy, and Biomaterials from Agricultural Waste Resources in South China, Agricultural Waste Resources. 2016;1(2):51-62.

31. Yates M, Ramos-Gomez M, Civantos A, et al. Beverage waste derived biomaterials for tissue engineering. Green Chemistry. 2017.

32. Gutierrez-Macias P, Hernandez DJ, Barragan-Huerta BE. The production of biomaterials from agro-industrial waste. Fresenius Environmental Bulletin. 2017;26(6):4128-4152.

33. Padmanabhan S K, Salvatore L, Gervaso F, et al. Synthesis and characterization of collagen scaffolds reinforced by eggshell derived hydroxyapatite for tissue engineering. $J$ Nanosci Nanotechnol. 2015;15(1):504-509.

34. He L H, Standard OC, Huang TT, et al. Mechanical behaviour of porous hydroxyapatite. Acta Biomater. 2008;4(3):577-586.

35. Haider A, Haider S, Han SS, et al. Recent advances in the synthesis, functionalization and biomedical applications of hydroxyapatite: a review. RSC Advances. 2017;7(13):7442-7458.

36. Hall BK. Bones and cartilage: developmental and evolutionary skeletal biology. 2nd ed. Academic Press; 2005
37. Akram M, Ahmed R, Shakir I, et al. Extracting hydroxyapatite and its precursors from natural resources. Journal of materials science. 2014;49(4):1461-1475.

38. Hiller JC, Thompsom TJU, Evison MP, et al. Bone mineral change during experimental heating: an X-ray scattering investigation. Biomaterials. 2003;24(28):5091-5097.

39. Kim SK, Park PJ, Kim YT. Study on acute subcutaneous toxicity of hydroxyapatite sinter produced from tuna bone in Sprague-Dawley rates. Life Science Journal. 2001;11(2):97-102.

40. Mandal N, Mondal S, Mondal A, et al. Response surface modeling of Cu (II) removal from wastewater using fish scale-derived hydroxyapatite: application of Box-Behnken experimental design. Desalination and Water Treatment. 2016;57(33):15410-15423.

41. Castro P, Huber M E. Marine biology. 6th edn. New York: McGraw-Hill Higher Education; 2008. 460 p.

42. Wu T, Shu T, Kang L, et al. Icaritin, a novel plant-derived osteoinductive agent, enhances the osteogenic differentiation of human bone marrowand human adipose tissue-derived mesenchymal stem cells. Int $\mathrm{J} \mathrm{Mol}$ Med. 2017;39(4):984-992.

43. Walsh PJ, Buchanan FJ, Dring M, et al. Low-pressure synthesis and characterisation of hydroxyapatite derived from mineralise red algae. Chemical Engineering Journal. 2008;137(1):173-179.

44. Goloshchapov DL, Kashkarov VM, Rumyantseva NA, et al. Synthesis of nanocrystalline hydroxyapatite by precipitation using hen's eggshell. Ceramics International. 2013;39(4):4539-4549.

45. Zhou H, Yang M, Zhang M, et al. Preparation of Chinese mystery snail shells derived hydroxyapatite with different morphology using condensed phosphate sources. Ceramics International. 2016;42(15):16671-16676.

46. Frankly. Hydroxyapatite Market by Key Players, Product and Production Information Analysis and Forecast to 2022. 2018

47. Pighinelli L, Kucharska M. Chitosan-hydroxyapatite composites. Carbohydrate polymers. 2013;93(1):256-262.

48. Oladele IO, Akinola OS, Agbabiaka OG, et al. Mathematical Model for the Prediction of Impact Energy of Organic Material Based Hydroxyapatite (HAp) Reinforced Epoxy Composites. Fibers and Polymers. 2018;19(2):452-459.

49. Ramakrishna S, Mayer J, Wintermantel E, et al. Biomedical applications of polymer-composite materials: a review. Composites science and technology. 2001;61(9):1189-1224. 